\title{
A metáfora do espetáculo vertical: um olhar para a cidade de Campina Grande-PB
}

\author{
The metaphor of the vertical spectacle: a look at the city of \\ Campina Grande-PB
}

Thaís Marculino da Silva[a] (1), Ângela Maria Cavalcanti Ramalho[b] ()

[a] Universidade Estadual da Paraíba (UEPB), Campina Grande, PB, Brasil

[b] Universidade Estadual da Paraíba (UEPB), Departamento de Ciências Sociais, Campina Grande, PB, Brasil

Como citar: Silva, T. M., \& Ramalho, A. M. C. (2020). A metáfora do espetáculo vertical: um olhar para a cidade de Campina Grande-PB. urbe. Revista Brasileira de Gestão Urbana, 12, e20190222. https://doi.org/10.1590/21753369.012.e20190222

\section{Resumo}

Este estudo tem como objetivo espacializar o processo de verticalização na cidade de Campina Grande-PB associando-o à dinâmica teórica da metáfora do espetáculo e, a partir desse cenário, evidenciar as possíveis implicações socioeconômicas e ambientais derivadas desse processo na perspectiva dos atores envolvidos. A metodologia em função dos objetivos, adotada na construção desta pesquisa, foi a exploratória-descritiva, a partir da abordagem de análise qualitativa. Ademais, a pesquisa foi conduzida através de um estudo de campo, apropriando-se da observação direta não participante e do uso de entrevistas. Observou-se que a proliferação dos edifícios, mediante a dinâmica do espetáculo vertical, gera a presença de uma imagem cada vez mais percebida pelos indivíduos, que proporciona a sensação de aspiração ao progresso local, evidenciando transformações na paisagem urbana e também no constructo do ideário da sociedade, a qual, com maior aderência, passa a idealizar este modelo de mercadoria. Por outro lado, este cenário promove implicações que perpassam desde a sensação de isolamento do convívio com a cidade até a percepção de uma espacialização vertical local desordenada, bem como a sobrecarga no uso dos recursos naturais, de forma que a construção desse cenário espetacular se desenvolve sob limitada preocupação ambiental, submetida ao cálculo das racionalidades econômicas.

Palavras-chave: Metáfora do espetáculo. Imagem. Espetáculo vertical. Implicações socioeconômicas e ambientais.

\section{Abstract}

This study aims to spatialize the verticalization process in the city of Campina Grande-PB associating it to the theoretical dynamics of the spectacle metaphor and from this scenario, evince the possible socioeconomic and environmental implications derived of this process as of the perspective of the actors involved. The objective-based methodology adopted in the construction of this research was exploratory-descriptive, which was based on the qualitative analysis approach. Moreover, the research

TMS é economista, mestre em Recursos Naturais, especialista em Gestão Empreendedora e Inovação, professora substituta, e-mail: thais.marculino48@gmail.com

AMCR é doutora em Recursos Naturais, professora titular, coordenadora, e-mail: angelamcramalho@gmail.com 
was conducted through a field study by non-participant direct observation and interviews. It was observed that the proliferation of buildings through the dynamics of the vertical spectacle generates the presence of an image increasingly perceived by individuals. Thus, this factor provides the feeling of aspiration to local progress, evincing changes in the urban landscape, and also in the construct of the ideology of society, which with greater adherence comes to idealize this commodity model. On the other hand, this scenario promotes implications that range from the feeling of isolation from living with the city to the perception of a disordered local vertical spatialization, as well as the overload in the use of natural resources, so that the construction of this situation develops under limited environmental concern, subjected to the calculation of economic rationalities.

Keywords: Metaphor of the spectacle. Image. Vertical spectacle. Socioeconomic and environmental implications.

\section{Introdução}

A metáfora do espetáculo apresenta-se, sob o ponto de vista da análise, como uma categoria teórica que evidencia o processo de acumulação capitalista a partir da construção de cenários e imagens, em que o espetáculo não se resume apenas à proliferação de um conjunto de imagens, mas revela-se a partir da concepção de que a imagem já dominou o campo visual da sociedade a tal ponto que as relações sociais e de produção passaram a ser mediadas por imagens (Debord, 1997).

Dentro desse contexto, o meio urbano passou a apresentar-se como palco privilegiado da dinâmica do espetáculo. 0 diferencial competitivo disseminado por peças publicitárias e envolto em uma dinâmica em torno da image-marketing vem promovendo a cenografia urbana, cristalizada através de atributos e artifícios presentes nas cidades, como, por exemplo, em equipamentos urbanos atrativos, na revitalização do espaço urbano, em melhorias estremes de infraestrutura, em espaços seletivos de consumo, em imóveis dotados de diferenciais competitivos, além da presença de arquitetura espetacular e apelos simbólicos, especialmente amparados em motes, como o da sustentabilidade, e que, na contemporaneidade, encontra na figura do edifício um de seus principais refúgios (Jacques, 2003; Maia, 2005; Paz, 2011). Assim, a promoção de transformações no meio urbano confere à cidade uma dada imagem, que se torna perceptível ao campo visual dos indivíduos e que, em grande medida, passa a mediar as relações socioeconômicas dos mesmos.

Nesse sentido, o edifício é artefato compositivo do espetáculo urbano, elemento ideal para a construção de imagens modernas, ao mesmo tempo em que abriga em si características espetaculares, que o tornam cada vez mais atrativo. Tais características, consolidadas pelas estratégias de marketing, em grande parte, reorientam o comportamento da demanda ao influenciarem as preferências do consumidor, acoplando ao valor de uso do bem, novas necessidades de signo.

Na sociedade do consumo (Bauman, 2008), o "morar e viver bem" reúne um conjunto de elementos econômicos, culturais e subjetivos. Envolto na simbologia e significação social, comprar um apartamento é um sonho que proporciona conforto, status, distinção social e estilos de vida que diferenciam o indivíduo. Assim, a dimensão simbólica está relacionada ao prazer de consumir determinada mercadoria e, na contemporaneidade, não se consome apenas pela utilidade, mas também pelo valor de signo, ou seja, o que compramos como bem de consumo deve estar imbuído de valores simbólicos, como, por exemplo, a distinção social (Slater, 2002; Retondar, 2008).

Engendram-se, assim, os mecanismos de mercado, conservando-se a lógica do desenvolvimento capitalista, pois, ao proliferar-se a construção de edifícios espetaculares, se permite a elaboração de um cenário verticalizado. Esse cenário, fruto das relações sociais e de produção, adquire profusão entre os agentes, por meio das ferramentas de marketing, consubstanciando a formação de uma imagem, a imagem da cidade verticalizada. Diante desse cenário, a imagem repleta de signo e simbologia invade o cotidiano da vida na cidade, (re)orientando as necessidades humanas e levando os agentes ao desfecho do consumo. 
A partir deste enquadramento teórico e fazendo um recorte geográfico do estudo, situa-se a cidade de Campina Grande-PB, cuja dinâmica em torno da produção e consumo do espaço urbano pode ser associada à problemática elucidada, salvaguardando as ponderações para o caso da cidade, que se configura como uma cidade de porte médio.

Apesar de o espaço urbano do município não estar completamente utilizado, o mesmo encontra-se em crescente expansão, caracterizando-se como um espaço atrativo-mercadológico, sobretudo para o ramo imobiliário. Nos últimos anos, Campina Grande vem se destacando, acompanhando o movimento de crescimento urbano dos municípios brasileiros, o que contribuiu para elevar a concentração da população residente na zona urbana, potencializando transformações em torno do espaço urbano, com especial destaque para a proliferação de empreendimentos verticais, como observado através de estudos desenvolvidos por Costa (2013) e Silva (2012).

Embora o embate teórico em torno da espetacularização associada aos empreendimentos verticais reproduza o caso de cidades metrópoles, em que se apresentam espaços concentrados de alta densidade construtiva, é mister observar a dinâmica das cidades médias, sobretudo quando assume-se que as tendências da cidade metropolitana se disseminam entre as cidades médias, mesmo que em menor escala.

Por outro lado, pode se inferir que as cidades médias, em parte, possuem uma necessidade menor de verticalização, sobretudo quando possuem espaços urbanos ainda disponíveis para expansão de uso e consumo, como é o caso de Campina Grande, o que, por sua vez, reforça a dinâmica da metáfora do espetáculo vertical, se considerarmos a necessidade de criação de uma imagem verticalizada como fator atrativo-mercadológico.

É mediante a esse contexto que o presente artigo possui como objetivo espacializar o processo de verticalização na cidade de Campina Grande, associando-o à dinâmica teórica da metáfora do espetáculo e, a partir desse cenário, evidenciar as possíveis implicações socioeconômicas e ambientais derivadas desse processo na perspectiva dos atores envolvidos. A metodologia em função dos objetivos adotada na construção desta pesquisa foi a exploratória-descritiva, a partir da abordagem de análise qualitativa. Ademais, a pesquisa foi conduzida através de um estudo de campo, apropriando-se da observação direta não participante e do uso de entrevistas semiestruturadas. Além desta breve introdução, o artigo encontra-se estruturado da seguinte maneira: na seção seguinte, apresenta-se uma discussão teórica acerca da metáfora do espetáculo e a interface com o processo de verticalização. Em seguida, apresentase a metodologia utilizada para a construção deste artigo. Na seção seguinte, os principais resultados e discussões, seguidos pelas considerações finais e referências bibliográficas.

\section{A metáfora do espetáculo vertical: caracterização e conceitos}

A espetacularização pode ser compreendida como um fenômeno social, cultural e economicamente construído, sendo representada por múltiplos polos de interesse, considerando que as necessidades sociais não são homogêneas e nem fixas, são criadas e recriadas em função, inclusive, da significação social, também dos avanços tecnológicos e no campo político, além evidentemente dos arranjos simbólicos e discursivos sociomidiáticos, apresentando-se, ao mesmo tempo, como sendo o resultado e o projeto do modo das relações sociais e de produção do capitalismo contemporâneo (Somekh, 1997).

De acordo com Debord (1997), a sociedade atual vive de forma contemplativa, pois está submergida em um mundo submetido às imagens que invadem todos os contextos da vida em sociedade. Em outros termos, assume-se que as relações sociais entre as pessoas são mediadas por imagens. Assim, as imagens corporificam o espetáculo, rendendo a este, as admirações do público espectador, ao render o público às tramas do espetáculo.

Para compreender a teoria do espetáculo, a partir das arguições críticas observadas em Debord (1997), é preciso considerar que o espetáculo é uma metáfora e não apenas uma crítica superficial para os indivíduos que o assistem e também para aqueles que nele atuam. Assim, a metáfora do espetáculo, tomando como base as representações cênicas, pressupõe que os indivíduos se encontram em posições 
distintas, ou seja, assumem diferentes papéis e diferenciadas funções, de sorte que uns encenam, outros assistem e outros produzem e dirigem o espetáculo. Porém, a desagregação entre atores, público e diretor de cena manifesta-se sobre um composto uno, consubstanciando, assim, a dinâmica do espetáculo. Em outras palavras, o espetáculo só se realiza diante da unicidade destes, mesmo estando estes devidamente separados.

Assim, observa-se que, embora a sociedade capitalista contemporânea possa ser observada através de distintas perspectivas, no que tange às divisões grupais, é mister considerar que a mesma estrutura-se especialmente a partir das relações de produção e consumo, ou seja, é dividida em classes produtoras e consumidoras de mercadorias, de maneira que tal estrutura, ao fundamentar o espetáculo, expressa-se em essência como sendo o resultado de relações sociais de um processo de produção, no qual a mercadoria, ao separar-se do seu produtor, adquire a liberdade da circulação (Marx, 1991).

Nessa esfera da circulação, a mercadoria adquire a leveza da imagem, espraiando-se pelo espectro do visível, de modo espetacular, distanciando-se cada vez mais de seu valor de uso e aproximando-se cada vez mais de valores simbólicos (re)criados e agregados à mercadoria, com o objetivo de suprir aparentes necessidades. Assim, não se pode conceber o espetáculo como sendo apenas o resultado de ações privadas e/ou públicas ou, em termos metafóricos, como resultado apenas de um corpo técnico de diretores e atores, mas devemos considerá-lo a partir da plenitude social, guiada e orientada pela dinâmica do desenvolvimento capitalista.

É diante desse cenário que Debord (1997) aprofunda as reflexões acerca das significações sociais em torno do campo do visível, no qual se insere a espetacularização, demonstrando o que, para ele, é o espetáculo: “[...] espetáculo não é um conjunto de imagens, mas uma relação social entre pessoas mediatizada por imagens". E, ainda, por se basear em relações sociais de produção, para o autor "[...] o espetáculo é o capital em tal grau de acumulação que se torna imagem" (Debord, 1997, p. 14, 25).

Resume-se, desse modo, a esteriotipização da vida social contemporânea, em que a realidade se fundiu à imagem, e a inversão do real ao espetáculo tornou-se mercadoria, tornando o espetáculo real. 0 espetáculo social tornou-se uma faceta do sistema, que, diante da sua capacidade de resiliência, se reinventa, promovendo as bases para manutenção do processo de acumulação em escala ampliada do capital.

Embora o espetáculo envolva todos os aspectos da vida em sociedade, o enfoque da análise do presente estudo se dá em torno do espetáculo vertical, o qual, na contemporaneidade, tem-se apresentado como uma das imagens cada vez mais assistidas e difusas em meio às transformações do espaço urbano e que, irremissivelmente, reporta às aspirações de avanço e progresso social, embora a verticalização se manifeste de forma observável, no âmbito urbano, desde o início do século XX (Nethercote, 2018).

A espetacularização associada aos imóveis verticais apresenta-se como efeito de determinada valorização subjetiva e objetiva do espaço urbano, bem como das suas células compositivas, através das ideias de status social, da sensação de segurança, conforto, dentre outros aspectos, especialmente observáveis em localidades dotadas de maior infraestrutura, como também associada a bairros com um perfil de renda mais elevado, potencializando, dessa maneira, a ideologia da sociedade do consumo (Bauman, 2008; Jacques, 2003; Padinha, 2013; Slater, 2002).

Assim, o edifício é, ao mesmo tempo, uma das imagens urbanas contemporâneas que compõem o espetáculo urbano, ao passo que, em si mesmo, apresenta-se cada vez mais, espetacular e suntuoso. Logo, o edifício espetacular pode ser observado através dos diversos atributos incorporados a ele e aos seus entornos, os quais também estariam imbuídos da presença de novos valores, simbologias e expectativas observados nas formas de se viver e morar na cidade. De acordo com Loureiro \& Amorim (2005) e Fonseca (2006), na contemporaneidade, residir em edifícios está relacionado diretamente com sonhos e ideários de status social, os quais majoritariamente passam a ser medidos e/ou caracterizados de acordo com os atributos embutidos nos mais estilosos arranha-céus que compõem as novas paisagens urbanas na atualidade. 
Embora a urbanização vertical, conforme aponta Nethercote (2018), não se desenvolva universalmente de forma padrão, ou seja, cada localidade apresenta suas especificidades, a intensificação desse fenômeno em sentido teórico e amplo pode ser associada às necessidades de mudanças nos artefatos culturais de distinção tanto na competição entre cidades quanto na geopolítica e nas relações de classe. Contudo, conforme aponta Oliveira (2012), a verticalização ocorre não apenas sob a perspectiva de ampliação do uso, ocupação e reprodução do espaço urbano. Muitas vezes, a expansão das construções verticais ocorre a partir de intencionalidades que visam propor uma nova imagem para a cidade, uma imagem mais moderna, e é dentro desse cenário que muitos edifícios são erguidos, ocupando a cidade em detrimento das edificações horizontais.

Nesse sentido, os caminhos para a promoção do espetáculo vertical urbano seriam perseguidos por estratégias de marketing que exploram valores externos ao objeto arquitetônico, como, por exemplo, a localização, a infraestrutura do local, em que os edifícios são implementados, com o intuito de valorizar o imóvel. Como aponta Padinha (2013, p. 77): “[...] as áreas mais bem-dotadas de infraestrutura e serviços também são as mais verticalizadas". Por outro lado, também seriam explorados valores internos ao edifício, como, por exemplo, a arquitetura, as áreas de entretenimento e convivência, atrelados à dimensão simbólica e às características dos apartamentos que, especialmente, estariam relacionados às dimensões de área, ao conforto e à segurança.

Para o autor, toda a "encenação" que compõe a arte do espetáculo urbano do se viver e morar em edifícios é respaldada e retroalimentada pela forte atuação do marketing, da publicidade e da mídia, apropriando-se inclusive de aspectos culturais da sociedade local para imprimir maior valorização tanto para o imóvel vertical quanto para a área onde o empreendimento está localizado. Assim, a metáfora do espetáculo, nesse contexto, está para além da simples imagem do edifício erguido na cidade, mas apresenta-se ao espectro do visível, através dos diversos atributos e artifícios presentes no e ao entorno dos edifícios, os quais basicamente são explorados em torno de estratégias desenvolvidas com base em diferenciais econômicos, sociais, culturais, ambientais e arquitetônicos.

Projeta-se a imagem do edifício como sendo o lugar ideal para viver e morar na cidade, de modo que a profusão dessa imagem insistentemente propagada pelas campanhas de marketing adquire espaço cada vez maior no ideário social, que passa a enxergar esse estilo de moradia como sendo o essencial para o suprimento de sua satisfação, induzindo ao aumento da procura por este tipo de mercadoria e, por conseguinte, levando ao aumento do consumo deste bem.

Nesse contexto, Loureiro \& Amorim (2005) afirmam que a produção de edifícios espetaculares eminentemente proliferados nas cidades fornece a construção de um imaginário de liberdade e glamour que fortalece o mercado imobiliário, cujo fundamento deriva da recriação contínua das expectativas em torno do morar, bem como de um certo estilo de vida. Dessa maneira, as peças publicitárias tanto representam o desejo dos indivíduos quanto a origem desses desejos, conduzindo a dinâmica do mercado de forma eficiente, evocando imagens e signos que sugerem conforto, segurança, estabilidade, tradição, riqueza, status.

Dessa maneira, a produção e a reprodução do espetáculo vertical pressupõem transformações nos hábitos e símbolos, e na paisagem urbana, diante de um ininterrupto processo de intervenções antrópicas que indistintamente definem, de forma sistemática, as incertezas produzidas pela sociedade atual e que afetam as interações socioambientais, o que nos leva necessariamente a refletir sobre.

É mediante a esta reflexão que se inserem as análises investigativas do presente estudo, buscando identificar as implicações socioeconômicas e ambientais derivadas do espetáculo vertical a partir da percepção discursiva dos atores envolvidos, tomando como pano de fundo o núcleo urbano da cidade de Campina Grande.

Propõe-se a compreensão da verticalização não ao aspecto do conteúdo, mas busca-se compreendê-la quanto à forma, considerando-a como algo não estático, mas essencialmente dinâmico. 0 objetivo não é o aprofundamento no fenômeno da verticalização em si, mas é trazer a proposta apoiada por um olhar diferenciado, não vinculando a verticalização apenas a questões da 
esfera econômica, mas conformando-a a partir de dada formação social e considerando-a a partir do embasamento teórico, como um cenário gerador de uma imagem espetacular para a cidade.

\section{Caracterização da área de estudo}

A cidade de Campina Grande está localizada na mesorregião do Agreste Paraibano, na Zona Centro-Oriental do estado, no trecho do planalto da Borborema, compondo o bioma da caatinga. A mesma é caracterizada como um centro submetropolitano e destaca-se por compor o segundo maior município em população do estado da Paraíba, o qual abriga cerca de 385.213 habitantes, exercendo influência na dinâmica política e econômica sobre os demais municípios do estado (IBGE, 2010).

Os estudos do Instituto Brasileiro de Geografia e Estatística ainda revelam que Campina Grande é classificada, na rede urbana, como uma cidade média, com nomenclatura específica: Capital Regional B19. Essa classificação pressupõe que a mesma apresenta uma expressiva influência na dinâmica da região, não apenas sobre os municípios vizinhos, mas também sobre grande parte do estado. De acordo com o estudo, para a classificação, são considerados critérios, como: função de gestão do território, níveis de centralidade do poder executivo e judiciário em escala federal, centralidade empresarial e a presença de diferentes equipamentos urbanos e serviços ofertados. Nos últimos anos, o município adquiriu destaque nacional através da construção do Complexo Aluísio Campos, um empreendimento que reúne a construção de moradias sociais (horizontais e verticalizadas), associadas a um polo industrial e tecnológico na zona sudeste do município, às margens da rodovia BR-104.

As recentes configurações em torno do espaço urbano do município de Campina Grande vêm alterando a paisagem da cidade, fato que se evidencia não apenas no espectro do visível, mas que também pode ser observado a partir de alguns estudos desenvolvidos por Costa (2013) e Silva (2012), os quais evidenciam que a cidade vem em franco processo de verticalização nos últimos anos, com destaque para a malha urbana do centro urbano, mas que também se dá de forma espraiada para as demais regiões da cidade.

A partir da metodologia da observação não participante, corroborada pela literatura, surgiu o interesse de analisar o contexto da cidade de Campina Grande. Observa-se, que grande parte da oferta desses empreendimentos verticais na cidade, abriga não apenas características em torno da funcionalidade de uma moradia, mas passou a incluir aspectos e valores simbólicos, como por exemplo, segurança, praticidade, conforto, lazer, status, preservação ambiental, dentre outros, com a observância de grandes arranha-céus dotados de uma arquitetura moderna e atraente, combinados também a equipamentos e atributos observados no entorno dos edifícios, como, por exemplo, boa localização e infraestrutura.

Esse cenário leva a inferir que as transformações em torno do espaço urbano do município não são perceptíveis apenas ao sentido da observação da paisagem, ou seja, a partir da geração de uma imagemsíntese da cidade, mas remetem a transformações, também, no que diz respeito aos hábitos de consumo e simbolismos presentes no constructo do ideário social local, pois pode-se inferir que mesmo em meio às necessidades de se dar vazão aos investimentos do mercado imobiliário vinculados ao mercado financeiro, vê-se que, se o movimento de oferta de tal estilo de moradia vem ganhando espaço no âmbito da cidade, presume-se, a partir do axioma das leis de mercado, que a demanda, em grande medida, tem fornecido respostas positivas, mediante a ação para o consumo.

Portanto, a partir da observação direta não participante, corroborada pela recente literatura, e o uso de entrevistas realizadas junto à Secretaria de Obras do município, buscou-se delimitar a área de estudo, identificando os bairros de maior concentração vertical. A pesquisa identificou e delimitou a construção de três perímetros urbanos com o objetivo de espacializar e mensurar as áreas de maior concentração de edifícios, na cidade, e que pudessem ser associadas ao embate teórico da pesquisa. Assim, para demarcar os perímetros escolhidos, apropriou-se da técnica de amostragem por julgamento, uma vez que a escolha das áreas de análise se deu de forma intencional, a partir da crença de que a amostra é representativa e 
possui maior significado para o estudo, tomando por base as entrevistas, as quais foram confrontadas pelo método da observação direta não participante.

Chegou-se às áreas de referência que consubstanciaram a espacialização da área de estudo, observada através da Figura 1, em que foram selecionados seis bairros da cidade de Campina Grande, a saber: 1 - Alto Branco; 2 - Lauritzen; 3 - Prata; 4 - Centro; 5 - Catolé, e 6 - Mirante. Em seguida, foram delimitados três perímetros de análise, de sorte que a criação dos perímetros escolhidos só foi possível devido à continuidade territorial que existe entre os bairros.

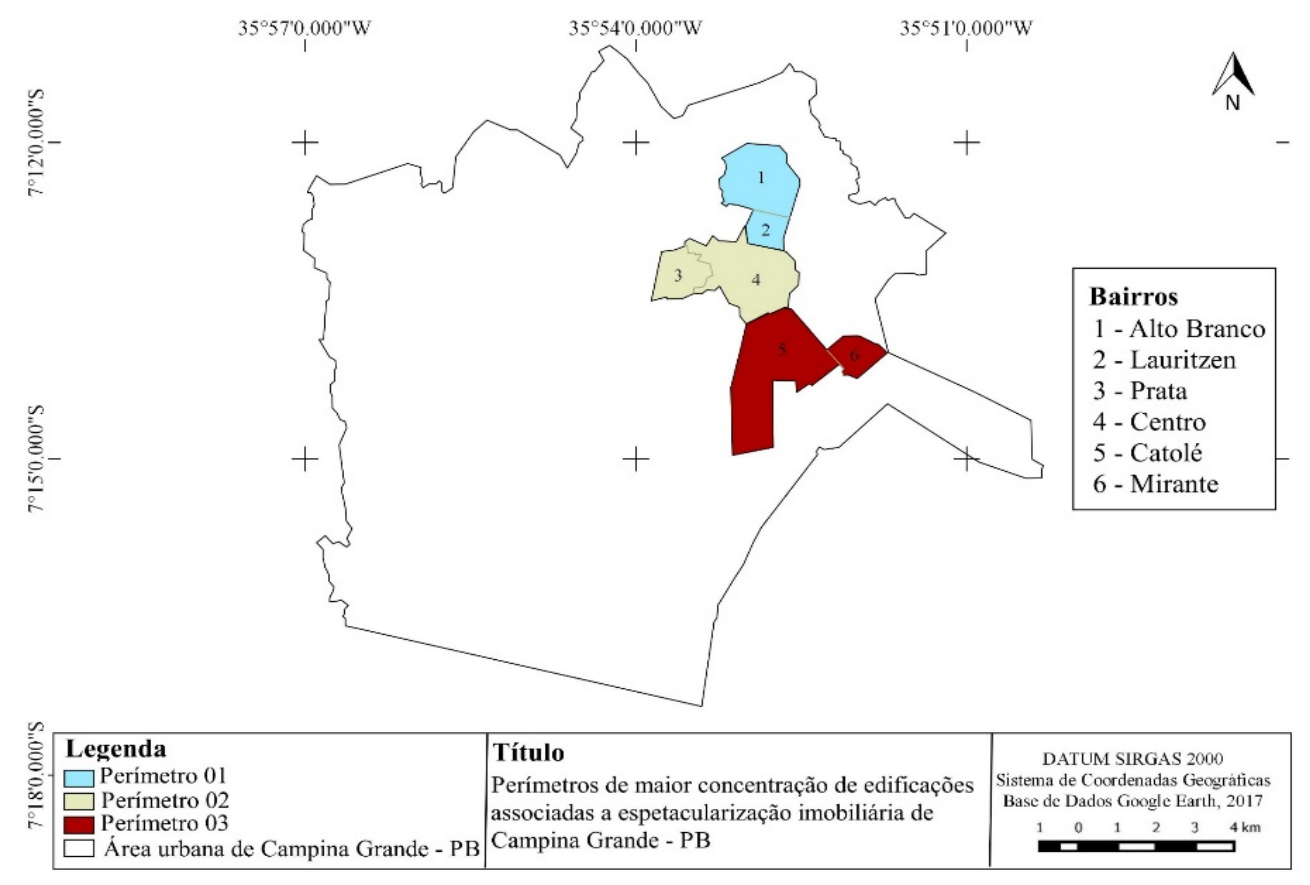

Figura 1 - Delimitação da área de estudo. Fonte: Autores (2019).

A identificação e a quantificação dos edifícios se deram de forma direta, por meio da pesquisa de campo, pela qual, através dos mapas dos seis bairros selecionados, percorreram-se os logradouros. Com o auxílio do Sistemas de Posicionamento Global - GPS, uma tecnologia de tratamento e manipulação de dados geográficos, coletaram-se as coordenadas geográficas de cada edifício, os quais são apresentados através do conjunto de Figuras 2, 3 e 4.

Para a delimitação da amostragem dos edifícios, estabeleceram-se alguns critérios. Assim, a pesquisa se limitou a mensurar os edifícios voltados para moradia, de modo que edifícios comerciais e/ou empresariais, ou ainda de uso misto, não foram captados, desconsiderando também os edifícios residenciais com fachada ativa. Cabe ressaltar que a pesquisa de campo delimitou-se ainda à coleta de edifícios que ofertassem algum diferencial competitivo, para além do fornecimento de apartamentos voltados para a moradia, como, por exemplo, área de lazer, biblioteca, salões de festa etc. Atentou-se também para que os edifícios, ao olhar da observação direta não participante do pesquisador possuíssem também um fino acabamento arquitetônico, evidenciando certa suntuosidade ao campo do visível, e deste modo, enquadrando a amostra coletada às digressões teóricas do presente estudo.

Além da coleta das coordenadas geográficas de cada edifício, inserindo-as em seus respectivos perímetros, a pesquisa também realizou uma classificação dos edifícios de acordo com a quantidade de pavimentos, fazendo duas distinções: a primeira considerando os edifícios que possuem entre quatro e oito andares, e a segunda classificação considerando os edifícios com mais de oito andares.

Assim, foram elaborados mapas dos perímetros urbanos delimitados na pesquisa, com base na coleta dos dados da etapa anterior. Os mapas foram produzidos a partir do uso do software de geoprocessamento QGIS, um programa de Sistema de Informação Geográfica com código aberto e licenciado sob a Licença Pública Geral (GNU). Com o uso dessa tecnologia, foram gerados mapas nos quais 
pode-se observar a espacialização de áreas com maior concentração de construções verticais localizadas ao longo do perímetro urbano selecionado do município, e que, a partir dos critérios da pesquisa, podem ser associados à dinâmica teórica da metáfora do espetáculo vertical.

Após a espacialização dos edifícios associados à dinâmica teórica do espetáculo, foram aplicadas entrevistas semiestruturadas, com o objetivo de identificar, através do discurso dos próprios atores envolvidos, ou seja, os moradores, possíveis implicações socioeconômicas e ambientais derivadas da proliferação do espetáculo vertical na cidade. Para seleção dos moradores entrevistados, a amostragem foi não probabilística, guiada pela técnica do snowboll, na qual um sujeito selecionado de forma intencional indica outro sujeito para participar da amostra e assim por diante. No total, foram entrevistados 26 moradores residentes em 18 edifícios, dos 156 apresentados na amostra coletada.

\section{Resultados e discussões}

\section{Espacialização dos edifícios verticais associados à dinâmica do espetáculo}

O conjunto das Figuras 2, 3 e 4 retrata a distribuição espacial para cada edifício coletado, bem como sua posição diante da área urbana em análise, ou seja, os perímetros 1, 2 e 3 delimitados na pesquisa, de modo que, ao longo dos perímetros estudados, foram coletados 156 edifícios. Desse total de edifícios, 91 são empreendimentos que comportam entre quatro e oito andares, e 65 são imóveis que possuem acima de oito andares.

Observa-se, a partir da Figura 2, que o perímetro 1 é a área com a menor concentração de edifícios vinculados à dinâmica do espetáculo vertical, apresentando 31 edifícios no total, em que se destaca o Bairro do Alto Branco por concentrar, quando comparado ao Bairro do Lauritzen, tanto a maior quantidade de edifícios com quatro e oito andares, num total de 13 edifícios, quanto em relação aos edifícios com mais de oito andares (seis edifícios).

Por sua vez, o perímetro 2 se destaca por ser a localidade que abrange a maior concentração de edifícios com mais de oito andares, perfazendo um total de trinta imóveis verticais. A maior parte desses arranha-céus está localizada no bairro central da cidade, especialmente no entorno de uma área nobre, próxima a um dos cartões postais da cidade, o Açude Velho.

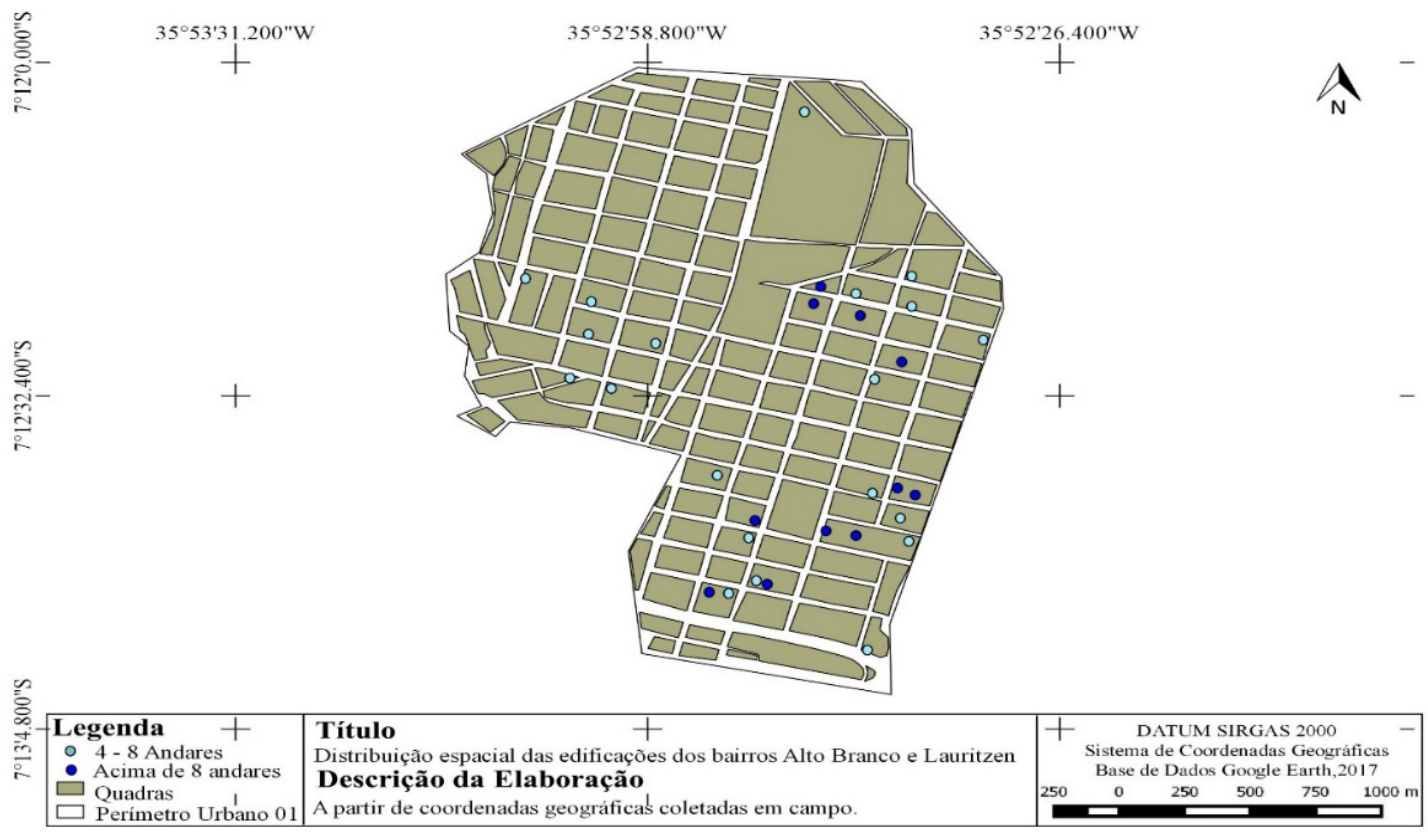

Figura 2 - Perímetro 01 (Alto Branco e Lauritzen). Fonte: Autores (2019). 
O Bairro Centro ainda adquire realce por congregar o maior quantitativo de edifícios para o perímetro em análise, 35 no total, quando comparado ao Bairro da Prata, conforme observado na Figura 3. 0 perímetro 3, que compreende os Bairros do Catolé e Mirante, se destaca como sendo a maior área de concentração de edifícios proeminente, possuindo 80 empreendimentos (Figura 4). Contudo, se destaca na categoria de edifícios com menor altura (4 - 8 andares), com 56 edifícios, embora seja o perímetro que ocupa a segunda maior concentração de imóveis verticais com mais de oito andares (24 edifícios), ficando atrás apenas do centro da cidade. 0 Bairro do Catolé se destaca, ainda, pela forte concentração de imóveis verticais, compreendendo 72 edifícios.

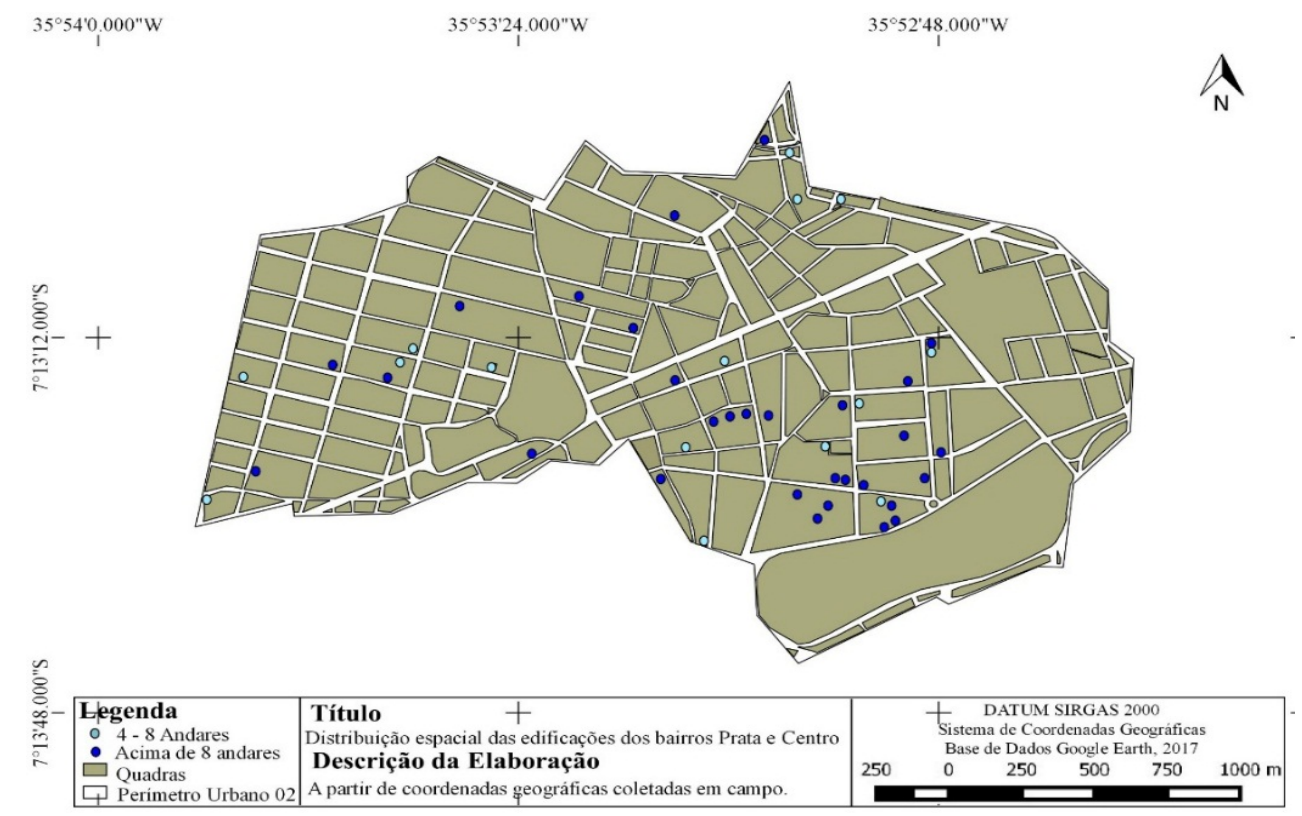

Figura 3 - Perímetro 02 (Prata e Centro). Fonte: Autores (2019).

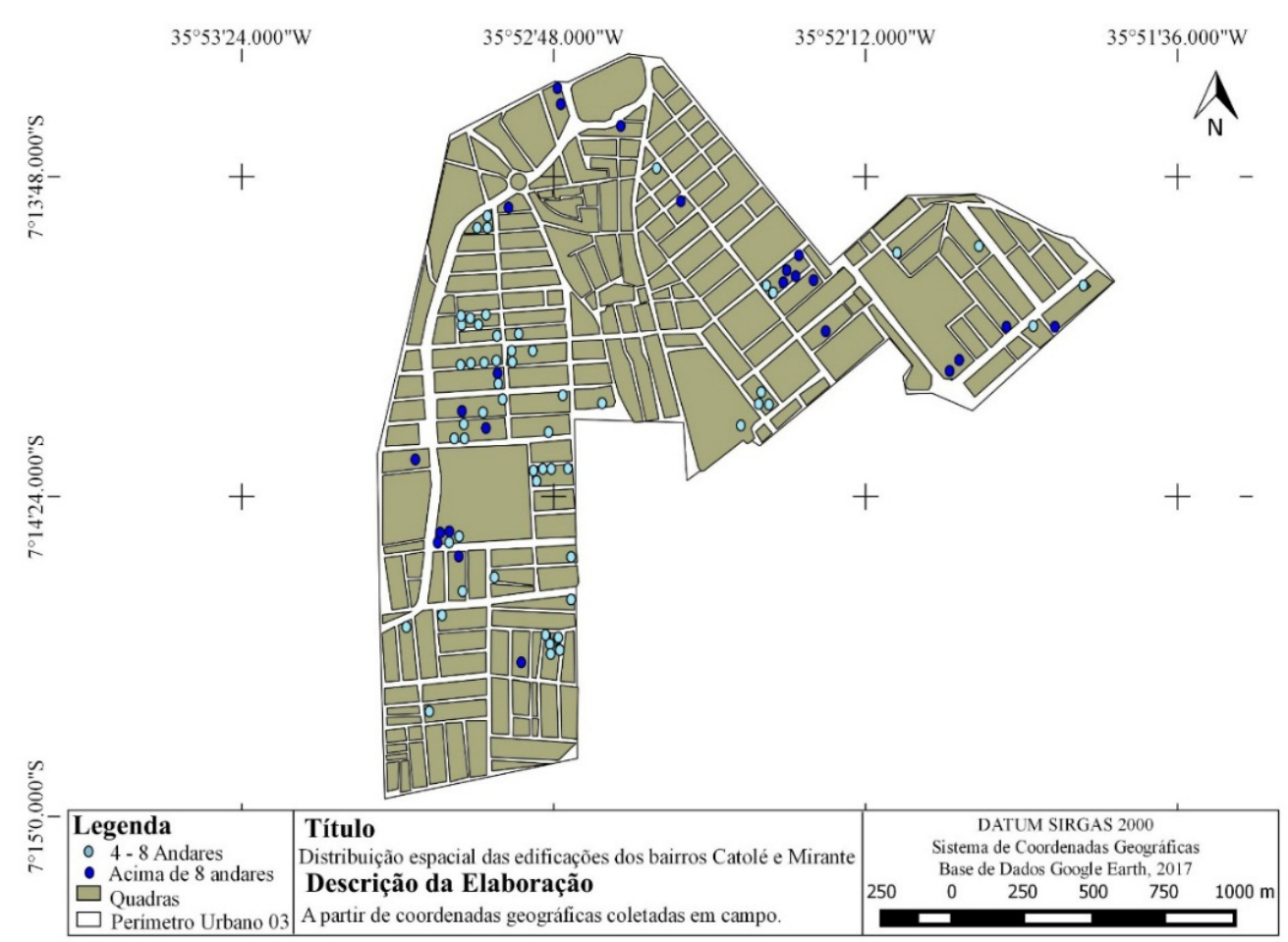

Figura 4 - Perímetro 03 (Catolé e Mirante). Fonte: Autores (2019). 
Em grande medida, a espacialização dos imóveis verticais ao longo dos perímetros estudados, bem como seu expressivo quantitativo, contribui para respaldar a análise de uma tendência à verticalização na cidade de Campina Grande, que pode ser melhor notada nos últimos anos. Tal evidência adquire maior robustez se levarmos em consideração que, para o enfoque da pesquisa aqui realizada, não se contemplou a coleta de edifícios comerciais/empresariais, de uso misto ou em processo de construção ao longo dos perímetros analisados, o que, de modo geral, remete ao entendimento de que o número dos imóveis verticais encontrados na cidade é bem mais significativo.

Outro resultado observado, em relação ao estudo apresentado, é que, embora essa tendência à verticalização, ao campo do visível, se dê de forma espraiada ao longo do espaço urbano de Campina Grande, verifica-se que a mesma possui uma forte concentração na malha urbana central do município, disseminando-se com mais evidência sobre os bairros com maior proximidade do Bairro Centro a partir das evidências da espacialização dos edifícios aqui apresentada.

Essas análises não apenas apontam para um processo de expansão da verticalização em si, mas, sobretudo, revelam que tipo de verticalização está se solidificando na cidade. Observa-se que essa tendência vem acompanhada de elementos que subsidiam a análise do espetáculo urbano, consubstanciando-o.

Assim, vê-se que a proliferação dos edifícios residenciais na cidade possui características que podem ser associadas à dinâmica teórica do espetáculo urbano, tendo em vista que, além das necessidades básicas de suprimento de uma moradia, neles podem ser observados novos simbolismos e signos demandados pelo constructo do ideário social acoplados a este bem, evidenciando que a expressão dessa tendência não se dá apenas no objeto arquitetônico difundido pela cidade, mas também expressa-se na formação do pensamento e nas necessidades da sociedade, que, com maior aderência, começa a idealizar este modelo de mercadoria. A anuência a este tipo de sentimento social retroalimentado pela difusão das imagens deste cenário espetacular conforma a criação de novas tendências ao consumo, fomentando, assim, o cenário do espetáculo vertical.

Esse contexto, a partir da perspectiva teórica observada em Debord (1997), Bauman (2008) e Slater (2002), entre outros autores abordados ao longo da fundamentação teórica, abre precedente para que as representações do espetáculo conquistem a admiração do público espectador, pois, ao inverter a realidade vivida, permite-se que a realidade objetiva seja cada vez mais dominada pela dinâmica do espetáculo, em que os indivíduos não compram mais apenas aquilo que é real, mas passam a comprar a magnificência que a mercadoria representa ao ser consumida.

A pesquisa adicionalmente se debruçou sobre a caracterização dos edifícios, buscando identificar também os principais elementos atrativos mercadológicos acoplados à oferta da moradia, tendo em vista que tal premissa foi adotada como critério para a espacialização do cenário vertical vinculado ao contexto do espetáculo.

Assim, dos 18 edifícios identificados nas entrevistas aplicadas junto aos moradores, foram coletadas informações que caracterizam os edifícios em análise. Dos 18 edifícios analisados ao longo das entrevistas, seis passaram a ser ocupados nos últimos quatro anos e os outros 12 edifícios funcionam há mais de 10 anos; porém, destes, apenas dois empreendimentos, um localizado no Bairro do Lauritzen e outro no Bairro Catolé, apresentam habite-se anterior aos anos 2000, o que, em grande medida, evidencia que, de fato, o aquecimento em torno da construção civil voltado para ampliação da oferta de edifícios verticais intensificou-se ao longo dos últimos anos. Geram-se, destarte, mais evidências do recente e expansivo processo de verticalização na cidade, conforme as proposituras teóricas.

Deste total de edifícios analisados, 10 possuem mais de oito andares, alguns chegando a apresentar 25 andares. A maioria, 10 edifícios, também se encontra avaliada como sendo edifícios de alto padrão, cuja aquisição de um apartamento custa entre $R \$ 500$ mil e $R \$ 700$ mil, com destaque para dois empreendimentos que apresentam apartamentos com cifras que giram em torno de $\mathrm{R} \$ 1$ milhão, expressando o considerável perfil de renda dos atores sociais que consomem essa mercadoria.

Cabe ressaltar que, dentre este total, 12 edifícios foram classificados como sendo novos e apenas seis passaram por obras de revitalização. Além disso, através da observação direta não participante, é 
possível inferir que os edifícios analisados apresentam perfil arquitetônico com fino acabamento, com destaque para as fachadas de vidro e o acabamento moderno.

No que tange ao conjunto de equipamentos atrativos que estão acoplados ao contexto da vivência nesse estilo de moradia, a Figura 5 demonstra as principais considerações da pesquisa, na qual foram identificados 16 equipamentos atrativos distintos e de uso comum nos edifícios analisados, com destaque para salão de festas, piscina, churrasqueira, parquinho e quadra esportiva.

Conforme observado na Figura 5, entre os 18 edifícios analisados, foi identificado, dentre os equipamentos com maior quantidade, que 17 edifícios possuem salão de festas, 15 possuem piscina, 14 possuem churrasqueira e 11 possuem quadras esportivas. Outros equipamentos também foram identificados e, apesar de se apresentarem em menor número, inserem-se como itens de maior diferencial e atratividade, como sala de cinema, sala de massagem e sauna.

Tais resultados revelam, conforme expõe Fonseca (2006), que os estilosos arranha-céus que compõem as novas paisagens urbanas na atualidade representam suntuosidade pelas suas características arquitetônicas e associadas aos diferenciais competitivos ofertados e acoplados aos edifícios, como, por exemplo, as áreas de lazer, nada mais são do que elementos e, ao mesmo tempo, a própria composição da espetacularização no empreendimento vertical.

Logo, as construtoras, de certo modo, captam as necessidades dos agentes econômicos ao mesmo tempo em que a difusão das imagens cria novas necessidades no ideário destes, de maneira que, passam a ofertar arranha-céus em excelentes localizações de Campina Grande dotadas de um considerável aparato de infraestrutura, próximas ao centro da cidade e que comportam diversos serviços internos, além de áreas de lazer, e que proporcione segurança. Por outro lado, a população envolvida na contemplação do espetáculo vertical, procura precisamente isto, um habitat moderno, seguro, que oferte diversos serviços, em um bom bairro, com uma infraestrutura consolidada.

Assim, os indivíduos produzem, contemplam e subsidiam o espetáculo quando conduzem diligentemente, dia após dia, a dinâmica de suas realidades sociais. Porém, a realidade vivida é constantemente invadida pelo fascínio do espetáculo, refazendo em si mesma a ordem espetacular da adesão positiva na sociedade, pois a realidade está submetida ao espetáculo ao mesmo tempo em que o produz. Como afirma Debord (1997, p. 15) “[...] o alvo é passar para o lado oposto: a realidade surge no espetáculo e o espetáculo no real", de forma que o envolvimento pelo cotidiano da vida espetacular não nos deixa perceber que o espetáculo da vida é o que nos conduz.

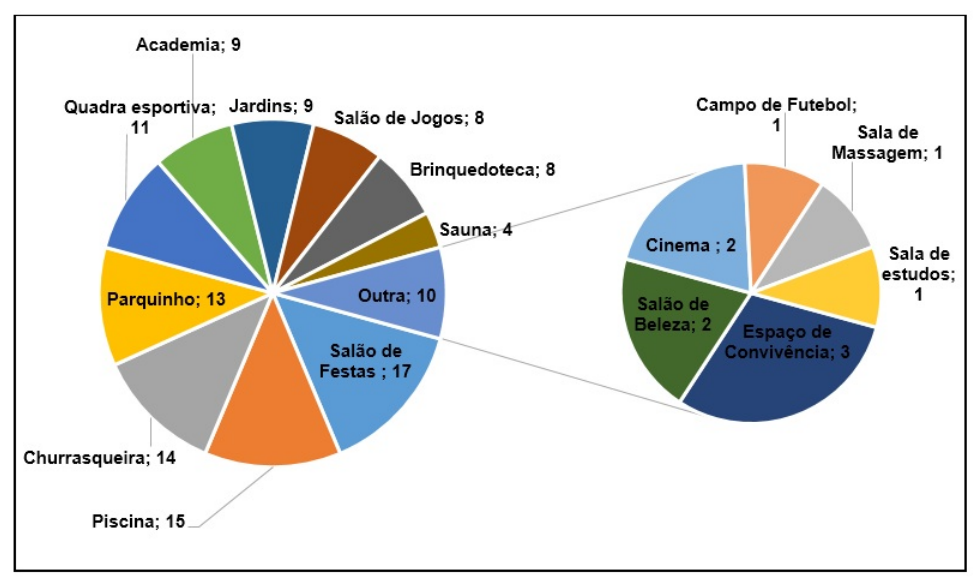

Figura 5 - Elementos atrativos identificados nos edifícios. Fonte: Autores (2019).

Dessa maneira, a produção e a reprodução do espetáculo vertical pressupõem constantes transformações nos hábitos e na paisagem urbana, ou seja, tanto na dimensão concreta quanto simbólica, diante de um ininterrupto processo de intervenções antrópicas que indistintamente definem de forma sistemática as incertezas produzidas pela sociedade atual e que afetam as interações socioeconômicas e ambientais. 


\section{Implicações socioeconômicas e ambientais}

A partir da espacialização da verticalização associada à metáfora do espetáculo, no núcleo urbano da cidade de Campina Grande, buscou-se identificar no discurso social dos próprios moradores quais as implicações tanto para a cidade quanto para a dinâmica da realidade de se viver e morar em meio ao cenário vertical. Os resultados obtidos foram sistematizados a partir da análise do discurso, considerando-se, ao longo dos discursos proferidos, a identificação de implicações em quatro categorias, a saber: social (Quadro 1), simbólica (Quadro 2), econômica (Quadro 3) e ambiental (Quadro 4), e separadas em duas dimensões: 1. Implicações do espetáculo vertical para a cidade; 2 . Implicações do espetáculo vertical no viver e morar em meio a este cenário.

Uma vez identificadas as implicações, mensurou-se o nível de intensidade com que estas apareciam na fala da amostra de moradores. Logo, o alto nível de representatividade social correspondeu ao destaque de implicações por, pelo menos, $50 \%$ da população entrevistada. Por sua vez, o nível médio de intensidade consistiu em uma representatividade de $30 \%$ a $49 \%$, e o baixo nível de intensidade correspondeu a um destaque de até $29 \%$ da população diante das implicações identificadas.

Assim, na categoria social, foram identificadas as seguintes implicações para a cidade: uma padronização da imagem da cidade, seguida por dificuldades de mobilidade urbana local, ou seja, nos bairros onde indivíduos moram, e desigualdade social. Para o nível da percepção individual, as implicações sociais identificadas foram: a existência de conflitos intrapessoais, os conflitos e dificuldades com a vivência coletiva, relacionamentos interpessoais aparentes e a maior incidência de riscos e acidentes, conforme se observa no Quadro 1.

Quadro 1 - Implicações sociais identificadas

\begin{tabular}{|c|c|c|}
\hline $\begin{array}{l}\text { Dimensões de atuação } \\
\text { das implicações }\end{array}$ & Implicações socais identificadas & $\begin{array}{l}\text { Níveis de } \\
\text { representatividade }\end{array}$ \\
\hline \multirow{3}{*}{ CIDADE } & Padronização da imagem da cidade & $\star \star \star$ \\
\hline & Dificuldades com mobilidade urbana local & $\star \star$ \\
\hline & Desigualdade social & $\star$ \\
\hline \multirow{5}{*}{ VIVER E MORAR } & Isolamento do convívio com a cidade & $\star \star \star$ \\
\hline & Conflitos Intrapessoais & $\star \star$ \\
\hline & $\begin{array}{l}\text { Conflitos Interpessoais e dificuldades com a vivência } \\
\text { coletiva }\end{array}$ & $\star \star \star$ \\
\hline & Relacionamentos Interpessoais aparentes & 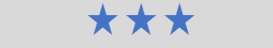 \\
\hline & Maior incidência de riscos e acidentes & 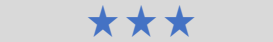 \\
\hline
\end{tabular}

Fonte: Autores (2019).

Destacam-se na percepção dos atores, em alto nível de incidência, dificuldades com o viver coletivamente, em meio a um convívio em que os relacionamentos, majoritariamente, são construídos sob a visão do aparente. Além disso, essa maior densidade populacional também reflete na percepção do sujeito de que os mesmos estão expostos à maior ocorrência de riscos e acidentes, a exemplo dos incêndios.

No discurso dos atores envolvidos, ainda foi possível identificar a sensação de padronização da imagem da cidade, evidenciando que o processo de verticalização é percebido pelos agentes, além de dificuldades com mobilidade urbana local e o sentimento de isolamento do convívio com a cidade, com indicação para o nível médio da representatividade dos moradores.

$\mathrm{Na}$ categoria simbólica, buscando apreender as implicações na formação do constructo do ideário social, foram identificadas as seguintes implicações para a cidade: embelezamento da cidade, perda da imagem de cidade interiorana, desenvolvimento, modismo e status. Já na dimensão individual, foram 
identificadas: a restrição da liberdade e da privacidade, a geração de uma pseudosegurança, além de simbolismos e signos em torno de aspectos como o status e a moda (Quadro 2).

Quadro 2 - Implicações simbólicas identificadas

\begin{tabular}{|c|c|c|}
\hline $\begin{array}{c}\text { Dimensões de atuação } \\
\text { das implicaçōes }\end{array}$ & Implicações simbólicas identificadas & $\begin{array}{c}\text { Níveis de } \\
\text { representatividade }\end{array}$ \\
\hline \multirow{5}{*}{ CIDADE } & Embelezamento da cidade & $\star$ \\
\hline & Perda da imagem de cidade interiorana & $\star \star \star$ \\
\hline & Desenvolvimento/Crescimento/Progresso & $\star \star \star \star$ \\
\hline & Modismo/Tendência & $\star \star \star$ \\
\hline & Status & $\star$ \\
\hline \multirow{4}{*}{ VIVER E MORAR } & Restrição da Liberdade & $\star \star \star$ \\
\hline & Restrição da Privacidade & 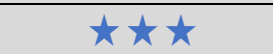 \\
\hline & Pseudosegurança & $\star \star \star$ \\
\hline & Status/Privilégio/Moderno/Moda & $\star \star$ \\
\hline
\end{tabular}

Fonte: Autores (2019).

No nível alto de representatividade individual, encontra-se uma forte restrição à privacidade para os indivíduos que vivem e moram nos edifícios. Por sua vez, na dimensão macro, o alto nível de intensidade é destaque para a implicação associada a uma crescente imagem de que o cenário vertical implica em desenvolvimento, crescimento ou progresso para a cidade. De modo mais específico, observou-se que, basicamente na fala de $90 \%$ dos moradores entrevistados, a expansão de edifícios verticais implica em uma imagem de progresso para a cidade.

No que diz respeito às implicações da categoria econômica, foi identificado que a montagem do cenário vertical incorre em um processo em que a imagem do cenário de verticalização ao campo do visível implica em uma espacialização desordenada, evidenciando que o planejamento urbano local apresenta deficiências na percepção do discurso social, sendo esta implicação destacada em nível médio pela população (Quadro 3).

Quadro 3 - Implicações econômicas identificadas

\begin{tabular}{|c|c|c|}
\hline $\begin{array}{l}\text { Dimensões de atuação } \\
\text { das implicações }\end{array}$ & Implicações econômicas identificadas & $\begin{array}{l}\text { Níveis de } \\
\text { representatividade }\end{array}$ \\
\hline CIDADE & Planejamento urbano desordenado & $\star \star \star$ \\
\hline VIVER E MORAR & $\begin{array}{l}\text { Probabilidade de endividamento devido às taxas do } \\
\text { condomínio }\end{array}$ & $\star$ \\
\hline
\end{tabular}

Fonte: Autores (2019).

Contudo, cabe destacar que a cidade de Campina Grande possui instrumentos que regulam o planejamento urbano em relação ao uso do solo e sua ocupação, como o Plano Diretor e o Código de Obras. Esse resultado remete à reflexão em torno do tratamento da gestão pública em relação à construção desse cenário do espetáculo vertical para a cidade, que deve estar pautado em formas de gestão que visam não apenas à lucratividade para alguns agentes, mas que agreguem, ao modelo da gestão pública municipal, a negociação, a confiança e a comunicação sensata entre os diversos agentes econômicos que compõem a sociedade, inclusive considerando suas percepções acerca da cidade onde vivem e moram. 
Ademais, foi identificada, em nível baixo e em relação ao nível individual, a existência de uma maior probabilidade de os indivíduos adentrarem em um processo de endividamento financeiro, mediante a obrigatoriedade de pagamento sobre taxas de condomínio.

Quanto às implicações da categoria ambiental, não foi identificada nenhuma implicação com nível de representatividade baixo. No nível médio, destaca-se, na percepção dos moradores, que há uma intensa sobrecarga dos recursos naturais provenientes da expansão do cenário vertical espetacularizado, que passam a ser explorados para atender, cada vez mais, a esta demanda crescente (Quadro 4).

Quadro 4 - Implicações ambientais identificadas

\begin{tabular}{|c|c|c|}
\hline $\begin{array}{c}\text { Dimensões de atuação } \\
\text { das implicações }\end{array}$ & Implicações ambientais identificadas & Níveis de representatividade \\
\hline CIDADE & Sobrecarga dos recursos naturais & $\star$ \\
\hline VIVER E MORAR & Limitada preocupação com o meio ambiente & $\star \star \star$ \\
\hline LEGENDA: Níveis de representatividade $\star$ Baixo $\star \star$ Médio $\star \star \star$ Alto & \\
\hline
\end{tabular}

Fonte: Autores (2019).

Por outro lado, em um nível alto de representatividade, os resultados revelam que, na dinâmica de produção desse cenário, há pouca preocupação com o meio ambiente e com os impactos neste, estando a preocupação de ordem ambiental limitada a questões pertinentes aos aspectos legais e econômicos.

\section{Considerações finais}

As observações teóricas ao longo deste ensaio permitiram elucidar que a cidade, ao se apresentar como produto do espetáculo, passando a adquirir os contornos de uma mercadoria e revelando-se como palco cenificado, apropria-se do espaço concreto e cristaliza-o sob a forma de diversos cenários espetaculares, a partir de uma organização estética que visa promover o embelezamento urbano. Dentre as construções dos diversos cenários urbanos na contemporaneidade, nota-se a crescente presença das molduras de imagens verticalizadas, cada vez mais vistas e difundidas na cidade e que proporcionam, a ela, o chamariz das aspirações ao progresso.

Tais observações contribuíram para o entendimento de que o edifício, objeto da verticalização, não se limita a apresentar-se apenas como sendo uma imagem-síntese do cenário espetacularizado da cidade, mas, ao envolver-se na trama cênica deste espetáculo, exibe-se de forma monumental, atrativa e hipnotizante, sendo em si mesmo um espetáculo, montado para encenar o espetáculo urbano.

Diante da dinâmica do espetáculo vertical, abre-se espaço para observações em torno das implicações provenientes desse processo. Evidenciou-se que a dinâmica do espetáculo pressupõe não apenas implicações derivadas das transformações concretas sobre o espaço urbano, mas também promove transformações no constructo do ideário social, uma vez que a linguagem do espetáculo se dissemina através dos signos e simbologias acopladas às imagens amplamente difundidas no convívio social.

Apropriando-se do campo de análise da cidade de Campina Grande, o estudo a partir da análise teórica da metáfora do espetáculo vertical espacializou os empreendimentos verticais, teoricamente associados a esse contexto, e, nesse sentido, foram identificados 156 edifícios habitacionais distribuídos ao longo de três perímetros urbanos, os quais compreendem seis bairros (Alto Branco, Lauritzen, Prata, Centro, Catolé e Mirante), coletados a partir dos parâmetros do espetáculo, ou seja, edifícios dotados de artifícios e atributos que o valorizam para além de seu valor de uso, na medida em que também valorizam a imagem da cidade.

A partir da espacialização dos objetos arquitetônicos, foi possível verificar que a verticalização é um processo observável na cidade de Campina Grande, embora sua distribuição se dê de forma espraiada. Note-se que tal observação também é acolhida no discurso e na percepção dos agentes sociais envolvidos e que vivem em meio ao cenário do espetáculo vertical. Para além do processo de verticalização, o estudo 
demonstra o destaque para que tipo de verticalização está se consolidando na cidade, tendência que vem acompanhada de habitats dotados cada vez mais de infraestrutura e oferta de diversos serviços para além da funcionalidade de uma moradia, habitats modernos e suntuosos, evidenciando transformações não apenas na paisagem urbana, mas também na formação do pensamento e nas necessidades da sociedade local, que, com maior aderência, começa a idealizar e demandar este modelo de mercadoria. A anuência a este tipo de sentimento social retroalimentado pela difusão das imagens deste cenário espetacular conforma a criação de novas tendências ao consumo, fomentando, assim, o cenário do espetáculo vertical.

Dessa forma, excluindo-se as devidas generalizações, os resultados revelam uma série de implicações sociais, econômicas, ambientais e também na formação do constructo do ideário social que possuem significativa relação com o objeto de estudo. Foram observadas implicações socioeconômicas e ambientais tanto em meio ao contexto de morar e viver no cenário vertical quanto para a própria cidade. Estas implicações, derivadas da amplitude do espetacular cenário verticalizado, perpassam desde a sensação por parte dos moradores de uma padronização da imagem da cidade, seguida por dificuldades de mobilidade urbana local, além da existência de conflitos e dificuldades com a vivência coletiva. Somam-se a isso ainda, percepções de um maior embelezamento da cidade, porém ao mesmo tempo com a perda da imagem de cidade interiorana, mas que por estar se verticalizando está também em desenvolvimento.

Destacam-se ainda implicações percebidas acerca de uma intensa sobrecarga dos recursos naturais provenientes da expansão do cenário vertical espetacularizado, que passam a ser explorados para atender, cada vez mais, à demanda crescente por este tipo de mercadoria. No entanto, na dinâmica de produção desse cenário, observou-se por parte dos indivíduos, que há pouca preocupação com o meio ambiente e os impactos neste, estando a preocupação de ordem ambiental limitada a questões pertinentes aos aspectos legais e econômicos. Ou seja: constatou-se que a preocupação de ordem ambiental ainda é, em grande medida, vista como externalidade, limitada à exigência dos meios legais.

As investigações realizadas ao longo deste estudo constituem-se sob um caráter preliminar e buscam a correlação de um aporte teórico (a metáfora do espetáculo) a um fenômeno sociourbano (verticalização). Sugere-se, para a construção de trabalhos futuros, a adoção de uma abordagem que relacione a atuação do agente público na dinâmica de transformação socioespacial, com o intuito de buscar conclusões mais precisas a respeito do que foi discutido no presente trabalho.

\section{Agradecimentos}

Os autores agradecem à Coordenação de Aperfeiçoamento de Pessoal de Nível Superior (Capes) pelo apoio financeiro concedido para a elaboração deste artigo, sendo este parte integrante do estudo desenvolvido ao longo da Dissertação de Mestrado.

\section{Referências}

Bauman, Z. (2008). Vida para o consumo: a transformação das pessoas em mercadoria (C. A. Medeiros, Trad.). Rio de Janeiro: Zahar.

Costa, B. L. (2013). Estruturação da cidade de Campina Grande: as estratégias e intencionalidades do mercado imobiliário (Dissertação de mestrado). Universidade Federal da Paraíba, João Pessoa.

Debord, G. (1997). A sociedade do espetáculo e comentários sobre a sociedade do espetáculo (E. S. Abreu, Trad.). São Paulo: Contraponto.

Fonseca, H., No. (2006). 0 marketing e a espetacularização urbanística. In Anais do Seminário Internacional Planejamento Urbano no Brasil e na Europa. Florianópolis: ANPPAS. Recuperado em 1 de fevereiro de 2017, de http://www.anppas.org.br/encontro4/cd/ARQUIVOS/GT10-218-51-20080521113611.pdf 
Instituto Brasileiro de Geografia e Estatística - IBGE. (2010). Censo demográfico. Recuperado em 1 de fevereiro de 2017, de http://www.cidades.ibge.gov.br/xtras/perfil.php?lang=\&codmun=250400\&search=paraiba|campinagrande

Jacques, P. B. (2003). Patrimônio cultural urbano: espetáculo contemporâneo. Revista de Arquitetura e Urbanismo, 6(1), 32-39. Recuperado em 1 de fevereiro de 2017, de http://www.portalseer.ufba.br/index.php/rua/article/view/3229/2347

Loureiro, C., \& Amorim, L. (2005). Dize-me teu nome, tua altura e onde moras e te direi quem és: estratégias de marketing e a criação da casa ideal: parte 1. Revista Vitruvius, 58(6). Recuperado em 1 de fevereiro de 2017, de http://www.vitruvius.com.br/revistas/read/arquitextos/05.058/490

Maia, R. (2005). O espetáculo urbano carioca: entre a contemplação e a participação dos citadinos. In Anais do XII Congresso Brasileiro de Sociologia. Belo Horizonte: FAFICH/UFMG.

Marx, K. (1991). O Capital (J. A. Giannotti, \& E. Malagodi, Trad., Vol. I). São Paulo: Nova Cultura.

Nethercote, M. (2018). Theorising vertical urbanisation. Revista Journal City, 22(5-6), 657-684.

http://dx.doi.org/10.1080/13604813.2018.1549832.

Oliveira, G. A. S. (2012). Verticalização urbana em cidades médias: o caso de Santa Cruz do Sul - RS (Dissertação de mestrado). Programa de Pós-graduação em Desenvolvimento Regional, niversidade de Santa Cruz do Sul, Santa Cruz do Sul.

Padinha, M. R. (2013). A verticalização da imponência e a negação do espaço. Revista Geo Amazônia, 1(1), 81-92. http://dx.doi.org/10.17551/2358-1778/geoamazonia.n1v1p81-105.

Paz, W. R. (2011). Sociedade do espetáculo e formação humana: mercado, tecnologia e cultura (Tese doutorado). Programa de Pós-graduação em Educação, Faculdade de Educação, Universidade Federal de Goiás, Goiânia. Recuperado em 1 de fevereiro de 2017, de

https://ppge.fe.ufg.br/up/6/o/Tese_Weligton_Rodrigues_da_Paz.pdf?1337693182\%20\%20

Retondar, A. M. (2008). A (re)construção do indivíduo: a sociedade de consumo como "contexto social" de produção de subjetividades. Revista Sociedade e Estado, 23(1), 137-160. http://dx.doi.org/10.1590/S010269922008000100006.

Silva, C. S. (2012). Processo de verticalização da cidade de Campina Grande-PB: um crescente processo na urbanização e no crescimento (Monografia). Universidade Estadual da Paraíba, Campina Grande.

Slater, D. (2002). Cultura do consumo \& modernidade. São Paulo: Nobel.

Somekh, N. (1997). A cidade vertical e o urbanismo modernizador. São Paulo: Studio Nobel.

\section{Editor: Rodrigo Firmino}

Recebido: Dez. 14, 2019

Aprovado: Jan. 15, 2020 